marketing may need to be tailored to target others at risk, including men and urban and suburban congregants.

\section{EPIDEMIC FEATURES OF THE FALLS AMONG ELDERS IN CHINA DURING 2008 TO 2013}

'Zheng Xuan, ${ }^{2}$ Gao Xin, ${ }^{2}$ Deng Xiao. ${ }^{1}$ Shanghai JiaoTong University, China; ${ }^{2}$ Chinese Centre for Disease Control and Prevention, China

\subsection{6/injuryprev-2016-042156.491}

Background Injury is one of the most serious threat to public health. Among them, Falls have always been playing a pivotal role in the cause of injury, especially for elder people. So we evaluate the epidemiologic features of falls injury and death among elders in China during January 2008 to December 2013, and expect to provide reference for the prevention and treatment.

Methods Injury and death data of falls were collected from the monitoring death surveillance data sets in national disease surveillance system and hospital based national injury surveillance data sets, which published by the Chinese Centre for Disease Control and Prevention. SPSS software version 17.0 was used for descriptive analysis.

Results The National Disease Surveillance Points system (DSP) data base showed that in 2008-2013, fall-related mortality among elderly person is fluctuating from $41.75 / 100,000$ to $48.22 / 100,000$, which was about six times than that among the whole population. The fall-related mortality increased with ages, so did the proportion of fall-related death to injury death. Furthermore, to different age groups, the proportion of fall-related death to injury death of males fluctuated from a low of 29.5 percent to a high of 32.8 percent. The ratio of female fall-related death obviously increased with age, in 65-69 years old group, 75-79 years old group, and the 85 years old and over group, the ratio was $6.6 \%, 18.1 \%$ and $79.4 \%$ respectively. For those patients admitted to hospital for injury, fall is the most important reason. Elderly people makes up $54.4 \%$ to $56.6 \%$ of all the injury cases, which is higher than the ratio in whole-population $(30.1 \%-36.1 \%)$. The proportion of elders fall-related cases to injury cases also showed a growing trend with age.

Conclusions The aged people is the susceptible population of fall injury with a high mortality. Those people with advanced ages, especially those females are the main concern of fall-related injury.

\section{EPIDEMIOLOGICAL SURVEILLANCE OF ACCIDENTAL FALLS AT HOME AMONG THE ELDERLY IN FRANCE: CHUPADOM STUDY}

Linda Lasbeur, Gaëlle Pédrono, Laure Carcaillon, Bertrand Thélot. Santé Publique France, Saint-Maurice, France

\subsection{6/injuryprev-2016-042156.492}

Background The frequency of falls among the elderly and their severity represent a major public health issue, whether in terms of deaths, functional or psychological sequelae, and cost. In France, the proportion of elderly people aged 65 years and more represent $18 \%$ of the population (12.2 million). Life expectancy at birth is 79.2 years for men and 85.4 years for women. In metropolitan France in 2011, 9,412 deaths due to falls were reported, of which $90 \%$ in people aged 65 years old and more with a sex-ratio equal to 0.6 . It is necessary to further explore their risk factors for the implementation of effective preventive actions.

Methods Patients to be included in the study should be aged 65 years or more, suffering from an accidental fall at home resulting in hospitalisation. Prospective data collection will start in 2016 during six months in several French hospitals emergency services. Standardised questionnaires will collect the circumstances of the falls, socio-economic and demographic status, and health and home characteristics of the patients. A follow-up study will be carried out one year after the fall to evaluate sequelae.

Results This study aims at identifying the circumstances of accidental falls at home among the elderly and establishing profiles of fallers with the help of factorial analyses. The second part of the study will analyse the consequences of the falls one year later: recurrent falls, type of sequelae and disability, quality of life, depending on the initial severity of the fall and the profile of the faller.

Conclusions This study will contribute to the implementation of adapted preventive measures thanks to the profiles established.

\section{COHORT STUDY OF OSTEOPOROSIS AND FRACTURE RISK: ARE WE ACHIEVING BENEFIT WITH SECONDARY PREVENTION?}

${ }^{1}$ Llion Davies, ${ }^{2}$ Damon Berridge, ${ }^{2}$ Jane Lyons, ${ }^{2}$ Angharad Walters, ${ }^{1,2}$ Ronan A Lyons. ${ }^{1}$ Public Health Wales NHS Trust, Cardiff, UK; ${ }^{2}$ Farr Institute, Swansea University Medical School, Swansea, UK

\subsection{6/injuryprev-2016-042156.493}

Background Osteoporosis is a global disease with a 30-40\% lifetime risk of associated fractures according to the World Health Organisation. Osteoporosis incidence is likely to rise with ageing populations. Risk factor modification and medical treatments may reduce fracture risk. This work aimed to investigate the time to second fracture of patients receiving medical secondary prevention following index fracture compared to those that did not. Methods An observational study design involved the formation of an anonymised e-cohort utilising linked records. All low impact fractures in patients aged $>60$ years were identified from the Secure Anonymised Information Linkage database between 01/04/2009 and 31/12/2014. Index and secondary fractures were identified from the emergency department and inpatient data sets. Linkages were made to censor for migration and mortality. Linked primary care records identified patients that had received prescriptions for fracture prevention medications. Statistical analysis involved regression models with accelerated time adjustments.

Results Over 49,000 cases were included. Of these, 8,033 (16.1\%) had received medical treatment, the median age was 78 years (range 60-108) and 14,120 (28.4\%) were male. Receiving medical treatment was significantly associated with increasing age (OR 1.02, 95\% CI: 1.017-1.022, p < 0.001) and female gender $(\mathrm{p}<0.001)$. Secondary prevention was significantly and independently associated with lower hazard of second fracture (HR 0.25, 95\% CI: 0.15-0.41, p < 0.001).

Conclusions Secondary medical prevention was associated with a $75 \%$ reduction in the hazard of sustaining a second fracture. However, fewer than a fifth of patients received such treatment. Study limitations include selection bias and potential residual confounding as patients were not randomised. Future work should focus on groups most likely to benefit from secondary prevention treatment to better inform clinical practice. 